\title{
SOME PROBLEMS ASSOCIATED WITH THE TRANSMISSION OF SYPHILIS TO THE SECOND AND THIRD GENERATION*
}

By DAVID N. NABARRO, M.D., F.R.C.P., Med. Officer in charge of the Venereal Diseases Dept. The Hospital for Sick Children, Great Ormond Street, London.

THE consideration of this subject falls naturally into two parts, relating respectively to the periods prior to and subsequent to the discovery of the Treponema or Spironema pallidum by Schaudinn and Hoffmann in I905, and of the serum reaction by Wassermann, Neisser and Bruck in I906.

The observations and records made during the first period were of necessity entirely clinical or clinicopathological, but they were none the less of considerable importance. They lacked, however, the scientific accuracy and exactness of detail which the vast amount of pathological and serological work carried out during the past twenty years upon this subject has succeeded in bestowing upon many of the problems of syphilis. These recent studies have clarified our views on many doubtful points, and have also shed new light upon various aspects of the disease; nevertheless there are matters which are still sub judice and upon which diversity of opinion still exists.

Very soon after the introduction of syphilis into Europe the occurrence of the disease in newly-born children was recognised. According to Diday, Gaspard Torella, in I498, was the first to mention the existence of syphilis in new-born infants, but, like other writers of that period, he believed the disease was transmitted by an infected nurse. He says: "Hoc accidit propter mammas infectas," and evidently recognises transmission only by the contact of a local sore in the nurse with the mouth or some other part of the body of her nursling. Other writers of that period believed that the infection occurred solely through the nurse's milk.

Paracelsus, in 1529 , was the first to assert positively

* Based upon an address delivered before the Medical Society for the Study of Venereal Diseases on July I 5 th, I927. 


\section{TRANSMISSION OF SYPHILIS}

the hereditary nature of the disease, by specifying that in certain cases "fit morbus hereditarius et transit a patre ad filium."

Although several subsequent writers of the sixteenth century still adhered to the nurse's milk mode of transmission, others, such as Theodosius (I54I), Augier Ferrier (I553), and P. Haschardius (I554), expressed the belief that the disease was transmitted per generationem. This brings us to the next period, when most of the authorities apparently held that the infection was transmitted directly from the father to the child. This view doubtless owes its origin in great measure to the fact that the mothers of syphilitic children only rarely present symptoms or signs of syphilis and in the majority of cases give no history of the disease. Such mothers might conceivably have acquired an immunity through having harboured a syphilitic fotus, as Fournier and others of the older authors held, or they might actually have syphilis-but in a latent form-as Hutchinson suggested, and as most authorities to-day believe. This is the socalled germinative mode of transmission, which is believed to be the most likely one, or at least a possible or probable one, by Kassowitz, Baumgarten, Hochsinger, Neisser, and other syphilologists. The other possible mode of transmission, and that which most, but not all, recent authorities agree is the usual one, is the placental. With this mode of infection of the fotus it would follow that the mother of a syphilitic child must herself always be syphilitic. It is theoretically possible for the first infected child to be an instance of paternal infection, and that the mother is infected viâ the child. In subsequent pregnancies the child would be infected through the mother, and these would be instances of maternal syphilis, and the children the offspring of two syphilitic parents. Such a syphilitic mother could, however, give birth to a syphilitic child by a second syphilis-free husband. There is the third possibility that a mother becomes infected during the course of the pregnancy and infects the fœtus during gestation or at the time of parturition.

We are all agreed as to the importance of the clinical observations of the older authorities, vide Colles's law, which said that a congenitally syphilitic child could not infect its mother, whereas it could infect a healthy wet nurse; also the treatises of Fournier, Hutchinson and 


\section{BRITISH JOURNAL OF VENEREAL DISEASES}

others, which so materially advanced our knowledge of congenital syphilis. It is the last twenty years, however, since the discovery of the Spironema pallidum and the Wassermann reaction which have been most productive of important researches in this direction. As instances of the value of the application of these discoveries to some of the problems of syphilis, one may give the following: (I) the Wassermann reaction has shown that between 80 per cent. and 90 per cent. of the mothers of syphilitic children are Wassermann positive, and that these mothers must be looked upon as having syphilis; (2) as Neisser has shown experimentally, the probability of infection, as well as the clinical manifestations of the disease, when infection does occur, depend upon the site of inoculation. Inoculation of the skin was the most successful and produced a characteristic infection, whereas a subcutaneous inoculation was much less often successful, and when it was so, it produced a different type of the disease. This may explain the well-established fact that when a woman becomes infected during conception, and the spironema gains access to the uterine mucous membrane, the disease may assume a mild or latent form with absence of primary or secondary manifestations.

Neisser found also that the spironema multiplies freely in the testis. Nichols, Warthin and others have shown that even in the absence of clinical manifestations the testis is involved, so that the spironema is often present in the seminal fluid. This observation explains how it comes about that fathers with latent syphilis can introduce the disease into their families. Thus Cooke and Jeans found that nearly 40 per cent. of the fathers they examined gave a negative Wassermann reaction often when a previous infection was admitted. In my own series of I23 fathers of syphilitic children, as many as 74 or 60 per cent. have given negative Wassermann reactions.

Many of these fathers deny all history of syphilis, and some of them even the possibility of infection. Some, however, admit that they have had gonorrhœa, and I have often thought that if the spironema were introduced together with the gonococcus, the latter might so influence the genito-urinary mucous membrane that the type of syphilis could be modified or that the disease could be localised say to the testis. In such a case the patient might not know that he had ever contracted syphilis, and 


\section{TRANSMISSION OF SYPHILIS}

on examination his Wassermann reaction might be positive or negative.

An argument against the theory of paternal transmission and the early infection of the embryo is that the rapid multiplication of the spironema would give rise to serious effects in the fœtus, whereas, as is well known, the disease is often latent at birth and is manifested only after a varying period of incubation.

Basing his theory on recent experimental work, some of which I have already referred to, Rietschel has brought forward an interesting hypothesis to explain some of the phenomena of the transmission of congenital syphilis. He assumes that the endometrium is rendered more susceptible to infection by the spironema at the time the ovum ripens, and that the resulting infection is a localised one-affecting the wall of the uterus only. This would account for the abortions and early miscarriages which so commonly occur in syphilitic families. The fotus itself rarely shows evidence of syphilis before the seventh month. With repeated pregnancies the uterine disease becomes increasingly latent, so that eventually a syphilitic child is born. The child may be infected by extension of the uterine disease to the placenta before birth, or, as Rietschel thinks more frequently happens, infection takes place shortly before or at the time of birth during the gradual separation of the placenta from the uterus. The maternal and fœtal bloods then mix, and during the strong pains associated with the uterine contractions, the spironemata are carried in varying numbers into the fotal circulation. This would explain the latent period of the disease, which may be as long as twelve weeks, the variation depending mainly perhaps upon the number of spironemata transferred.

This hypothesis is very ingenious, and while it may correctly explain how the infection of the fœtus often takes place at birth, it does not explain the sequence of events which has occurred in several of my own cases in which the first pregnancy has resulted in the birth of a syphilitic child or of an apparently healthy child which on subsequent examination is found to have a positive Wassermann reaction. It appears to me that the natural history of the disease may be changing, either on account of modification of the virulence of the spironema or possibly as a result of the modern methods of treatment, 


\section{BRITISH JOURNAL OF VENEREAL DISEASES}

and that the typical syphilitic family history of early abortions followed by premature still-born children and eventually of a living but syphilitic child, and finally of healthy children, is not nearly so frequently seen to-day as was apparently the case in previous generations.

Reference should perhaps be made to the suggestion favoured by Routh, Wile, Pollitzer and others, that there is a resting stage, in the form of a spore or granule, of the spironema, which would render paternal transmission possible and even probable. Routh further seeks to explain the diminishing virulence of infection in succeeding pregnancies by an assumed action of chorionic ferments on the spironema.

We may now briefly consider the Wassermann reaction and flocculation tests.

One great advantage which the present generation of practitioners has over its forbears is that it has the Wassermann reaction and the various flocculation tests to help it in diagnosing syphilis. It is rather a remarkable fact, however, that in spite of the countless Wassermann tests which have been carried out during the past twenty years, and the numerous researches upon the nature of the reaction, the value of the test appears to be more or less empirical, and the nature of the Wassermann substance or antibody is still somewhat of a mystery; so also is its relation to the infecting organism.

Apart from these theoretical considerations, however, there can be no doubt about the immense practical value of the Wassermann test when reliably performed. I would emphasise the word reliably, because of the great importance of carrying out the test by an approved technique.* Most, if not all, competent authorities are agreed that a strongly positive Wassermann reaction (in the absence of yaws and possibly a few other tropical diseases) indicates syphilis. This, of course, does not necessarily mean that the condition for which the patient consults us is of a syphilitic nature, though it may be an indication to treat the patient on anti-syphilitic lines. A negative Wassermann, on the other hand, does not exclude syphilis even in the case of the congenital form of the disease. I have a case in my series of children which exemplifies this point. A child aged I year 7

* Vide Addendum for details of the Wassermann techn:que employed and the notation adopted in my work. 


\section{TRANSMISSION OF SYPHILIS}

months was brought to hospital on account of mental deficiency and inability to sit up. There was no history of infantile symptoms, such as rash, snuffles, or epiphysitis. The parents had both been previously married and had healthy children, so I was informed, though I did not have an opportunity of examining them. The father had a chancre eight years previously (six and a half years before the birth of the patient) and was treated for three years with medicines. The mother gave no history of any infection. On blood examination the parents both gave a strongly positive Wassermann reaction (4.4), but the child's blood was negative. On the assumption that the child had syphilis, which I think was justified, he was given three injections of neo-kharsivan (o.I grm. intravenously), and the blood was tested after each injection - each time with a negative result. The cerebro-spinal fluid was tested, and the albumen was found to be increased to $0 \cdot I$ per.cent.; sugar slight, cells ten small mononuclears per cubic millimeter; globulin absent and cultures sterile. The Wassermann reaction was negative : the Lange test was unfortunately not carried out, as I was not doing them at that time. The child developed whooping-cough and died at home, so that an autopsy could not be obtained. The doctor reported that it died of meningitis. This, I think, is a very instructive case.

In the absence of a positive Wassermann reaction and of the finding of the spironema, however, it might be permissible to regard this case as being one of syphilitic origin, but not of the actual transmission of the spironema to the child. It is possible that this is a case in which the germ plasm in one or other of the parents had become affected by the spironema or its toxins and so wrought harmful effects upon the child.

On the other hand, one may come across a case in which both parents have a negative Wassermann reaction and yet the child may suffer from active and even very well-marked syphilis. Browning and Mackenzie quote such a case of a child with active syphilis from which it died, whose father and mother both had negative Wassermanns, but the father had been treated for syphilis thirteen years previously. I have one interesting case in my series of a child who at the age of six was brought to hospital on account of acute mental derangement, which turned out to be due to juvenile general paralysis. The 


\section{BRITISH JOURNAL OF VENEREAL DISEASES}

child's blood and spinal fluid were both very strongly positive. The father's blood was quite negative, the mother's practically so, but gave a positive Kahn reaction. Then again one must bear in mind the fact that the Wassermann reaction may oscillate between strong positive and negative either during treatment or even without treatment. I have seen this happen in several of my cases.

If it be conceded that it is possible to have a case of syphilis with a negative Wassermann reaction, then a fortiori any patient showing a weak reaction should be regarded as a possible case of syphilis. My own practice is, and has been for several years, to inquire fully into the antecedents of such cases, and sometimes I have been successful in establishing the diagnosis. Let me give one such case which was discovered accidentally when doing a series of Wassermann reactions on normal children and on cases of nephritis.

L. K., aged five and a half years, was admitted to hospital on account of nephritis. There had been no symptoms suggestive of syphilis in infancy or early childhood, and the possibility of syphilis was apparently not considered by the physician in charge of the case. The first Wassermann test I made in May, I92I, was all but negative, and the same result was obtained a fortnight later. I then inquired into the history and found that the mother had had a still birth in I9I2; an eight months baby in I9I4, which lived two hours, and another stillborn eight months baby in rgrg. The mother's blood was tested and found to give a strong Wassermann reaction (4.4). The patient's blood was tested again in November, I92I, with a weakly positive result, but in April, I922, it was strongly positive (4.4). Other groups of cases, besides nephritis, which may give weakly positive reactions are those of mental deficiency, hydrocephalus, paralysis and those in which the teeth are suggestive of Hutchinson's or Moon's types. It often entails a considerable amount of labour and expenditure of time to get up the parents and families of such cases, to go fully into their histories and to examine their bloods, etc., but when we are searching after truth, no trouble should be considered too great, no expenditure of time unprofitable.

The Kahn test, to which I have referred, is so easily carried out that we perform it in a large number of cases. 


\section{TRANSMISSION OF SYPHILIS}

In treated cases it persists after the Wassermann reaction is negative as a rule, but in untreated cases it may be negative when the Wassermann reaction is weakly positive.

Let us now briefly consider the problem of familial neuro-syphilis and other syphilitic manifestations. Various authors have drawn attention to the prevalence of neuro-syphilis in certain families, the parents and the children often showing symptoms of similar or allied nervous disorder. As is well known, it has been suggested that there is a special neurotropic strain of the spironema which is thought to be responsible for the production of neuro-syphilis.

Some cases from my own series are the following :-

A brother and sister mentally well, but not physically robust; both with positive Wassermann reactions in the cerebro-spinal fluid. A boy with strong Wassermann reaction in his cerebro-spinal fluid, whose brother died of juvenile G.P.I. A father with tabes, whose boy is hopelessly backward mentally, and almost blind from interstitial keratitis. Then apart from C.N. system disease, I have a brother and sister who developed a curious swelling of the parotid or of glands over the parotid, not of an infectious nature, for there was an interval of several months between the occurrences. Other children, members of one family, have an absolutely fast Wassermann reaction, in spite of many injections and much mercury and other treatment. I am of the opinion that such occurrences are not necessarily due to any special strain of spironema, but that they may depend quite as much upon the similarity of soil upon which the spironema has grown, that is to say, the tissues of parent and child and of brother and sister.

\section{Transmission to the Third Generation}

There appears to be considerable difference of opinion amongst writers upon third generation syphilis. Stokes in his recent work on syphilis writes:-

"Fournier was a vigorous proponent for the conception that syphilis was transmissible to the third generation. Hutchinson, who had an equally large experience of syphilis, could not convince himself that the reported cases were above criticism. 


\section{BRITISH JOURNAL OF VENEREAL DISEASES}

" At precisely this point the matter stands to-day.

"The French accept third generation syphilis as authentic, and proceed to invoke even grandparental influence, while other observers report cases with or without reserved judgment.

"Personally I have yet to see a report which is beyond cavil. Even though the condition exists, it must be a negligible rarity in actual practice, for a healthy child of congenital syphilitic parents is the overwhelming rule."

Jeans, another American writer, says of transmission to the third generation that it is " practically impossible of satisfactory proof, though instances are reported from time to time."

Rietschel in his contribution to the recently published comprehensive volume on congenital syphilis edited by Jadassohn says :-

"I believe this event-transmission of congenital syphilis to the second generation-is by no means rare, but often difficult of proof in actual practice."

There can be no question about the presence of syphilis in three generations of a family, as many authors have reported cases, and I have about a dozen such families in my own series. It is, of course, very difficult, and often impossible, to exclude the possibility of syphilis in the father, because, as we have already seen, many of the fathers of congenitally syphilitic children have negative Wassermann reactions, and often give no history of syphilis. If we assume that it is the father who gives the child its congenital syphilis, then this must be an instance of paternal transmission. If the child gets it from the mother, who is herself a congenital syphilitic, then the syphilis has been transmitted to the third generation. If, on the other hand, the father is supposed to infect the mother, who then passes on the syphilis to the child, we must assume that the mother who is already suffering from congenital syphilis is capable of reinfection, which most authorities would consider was impossible, unless it be a case of super-infection, when the transmitted syphilis would be only one to the second generation.

I have one interesting case in my series of congenital syphilis in a man who assures me there is no possibility of an acquired infection in his case. The disease was 


\section{TRANSMISSION OF SYPHILIS}

transmitted to his children in a mild form ; the first child died at two months of wasting before my contact with the family, so that I am unable to state the cause of death. The second child had a rash, convulsions and wasting at five weeks. The Wassermann reaction was moderately strong (4.4.0.0) at that time, but on ten subsequent occasions, between I92I and I927, has always been negative. She had mercury treatment for nine and a half months, and is now a fine, healthy girl. I venture to think that if this child had not been seen at the age of five weeks, when her Wassermann was positive, but had been seen for the first time when she was, say, six months old, she would not have been regarded as a case of congenital syphilis, but as being a healthy child. The mother's blood has always been Wassermann negative (five times) even after a provocative injection of $0.4 \mathrm{gr}$. N.A.B. It seems to me this might be a clear case of paternal transmission of congenital syphilis. As a point of practical importance, I may add that I suspect congenital syphilis, even in the absence of stigmata, in a young mother whose blood remains strongly positive (4.4.4.4) after prolonged treatment. In such a case I inquire into her family history, and endeavour to test her parents and brothers and sisters-sometimes with successful results. This leads me to a further important problem. Can the children of a congenitally syphilitic parent, or indeed of parents with acquired syphilis, have syphilitic manifestations such as marasmus, malnutrition, obscure anæmia, various disorders of the nervous system, cirrhosis of the liver, early arterial disease, kidney diseases and so forth, and yet have a negative Wassermann reaction?

This could possibly be brought about in the manner foreshadowed in an earlier part of this paper, by the germ plasm becoming affected by the spironema or its toxin, so that without direct infection of the embryo harmful effects, leading to mal-development, would be produced. This type of the disease has sometimes been called " inherited" syphilis, as opposed to the congenital syphilis, in which the spironema is actually transmitted to the child (H. C. and M. H. Solomon). These authors state that they use the term " congenital syphilis" to indicate that " a direct transference of the treponema from parent to child took place at some period between conception and the child's existence independent of the

v.D. 


\section{BRITISH JOURNAL OF VENEREAL DISEASES}

body of the mother." The term hereditary syphilis they use in a narrow and restricted sense, referring to " changes in the offspring due not to active and direct infection, but to germinal defects caused by parental syphilis."

It may be that the value of treatment with mercury, arsenic or potassium iodide in these cases may be due to their alleged syphilitic basis. This brings us to the French point of view, which has been fully expounded in the recent book by Hutinel, called "Le terrain hérédosyphilitique," that there may be such a condition as a syphilitic diathesis or tendency, and if there be such a thing as a predisposition to tubercle, arthritis, etc., why not to syphilis? This point of view has not obtained many adherents in this country or on the Continent, but my own experience of this disease is tending to draw me in this direction, and I sometimes ask myself the question : " Can the possibility that one or both partners of a union may have this predisposition help to explain why in some families many syphilitic children occur, yet in others only one or two ?" I am making observations on the blood groups of the members of syphilitic families to see if any helpful data can be obtained in this way.

I will conclude my remarks with one more interesting case. A mother brought her family of five children home from Africa to consult one of my colleagues about one of the children. The child was a clear case of congenital syphilis, with periostitis of the tibiæ and interstitial keratitis. I examined the mother and all the children. The eldest child, aged fourteen, and the three youngest, aged nine, eight and six years respectively, were all healthy, and gave negative Wassermann reactions. The second child, the patient, was eleven years old, and had a strong Wassermann reaction. The mother's blood was quite negative, and she looked quite healthy. She informed me that her mother had had three stillborn children at full term, and that her father had been born in the Egyptian Army. In spite of her negative Wassermann, the possibility of her being a congenital syphilitic, though without stigmata, crossed my mind, and discussing the question with her she asked me the very pertinent question: "Is it possible for a mother (as a congenital syphilitic), without herself showing any signs of the disease, to transmit the disease to any of her children ?" I had to admit I could not answer her question. I think 


\section{TRANSMISSION OF SYPHILIS}

the cases I have quoted to you show how fortuitous the transmission of congenital syphilis may be, and it remains for future investigators to discover the laws and conditions governing such transmission. There is still a fruitful field for research upon this interesting aspect of the disease.

\section{ACKNOWLEDGMENTS}

I should like to thank my colleagues, past and present, at the Hospital for Sick Children, Great Ormond Street, for their kindness in permitting me to use the notes of their cases and also for referring many of their cases to me for treatment. I should like further to put on record my thanks for the help I have received in this work from my various assistants : the late Dr. A. G. Simmins, who for several years assisted me on the clinical side ; to Dr. B. Buckley Sharp, who succeeded him and has assisted me during the last five years on the clinical side ; to Dr. D. McClean for his valuable help with the pathological work since the year I924; to Miss Elsie Campbell, my confidential secretary and assistant in the V.D. clinic since its inception in January, I9I7; to the members of the Almoner's Department of the Hospital, and to the organisation and inspectors of the National Society for the Prevention of Cruelty to Children, who have done so much to get the patients to attend the clinic during the many years that they have been kept under observation; and lastly to all those other individuals, not forgetting the patients and their parents, who have helped in their own particular way to enable me to carry out this work.

\section{ADDENDUM}

\section{Technigue of the Wassermann Employed in THIS WORK}

UNTIL the end of the year I923, the method I employed was substantially the method No. 4, given in the Special Report Series No. I4 of the Medical Research Committee. The complement was obtained fresh from guinea-pigs; the antigen was prepared from heart muscle and reinforced with cholesterol. During the earlier years $2 \frac{1}{2}$ to 3 M.H.D. of amboceptor were used, but from I9I8 onwards 5 M.H.D. were used for sensitising the cells. From the beginning of the year I924, when most of the 


\section{BRITISH JOURNAL OF VENEREAL DISEASES}

pathological tests were carried out by Dr. D. McClean, the method recommended by Colonel Harrison has been in use. This is the method No. I given in the Report previously referred to. For diagnostic purposes I dilution of serum $I$ in $I 5$, with 3 and 5 units of complement, are employed, but in treated cases more information can be gained by using the two dilutions of serum, I in I5 and $I$ in 30 , each with 3 and 5 units of complement.

When four figures therefore are given in a Wassermann report, the first one, which is usually the highest, refers to the dilution of serum $I$ in $I_{5}$ and 3 units of complement, the second one refers to the serum $I$ in $I 5$ and 5 units of complement, the next, serum I in 30 and 3 units of complement, and fourth, serum $I$ in 30 and 5 units of complement. Furthermore, the amount of hæmolysis in each tube is expressed by the figures $0, \mathrm{I}, 2,3$, and 4 . o represents complete hæmolysis, and therefore negative reaction in that particular tube, 4 indicates complete absence of hæmolysis, which is a strongly positive reaction in that tube, and the numbers 3,2 , and I represent a gradually increasing amount of hæmolysis, with corresponding gradual reddening of the supernatant fluid when the tubes are examined on the following morning. If one thinks that the hæmolysis is not quite sufficient to be represented by the figures 3,2 , I, one could use the signs $3+, 2+, I+$ or $<4,<3$, etc., and lastly, if the tube is not absolutely clear, and yet there is not enough corpuscle sediment to be represented by the figure I, I usually call it $\odot$.

Thus a blood which showed absence of hæmolysis in all four tubes would be represented by 4.4 .4 .4 , and would be regarded as very strongly positive; if it were 4.4.I.o, it would be less strong, and so on until the o.o.o.o, were reached-which is quite negative.

In examining cerebro-spinal fluid, one uses varying dilutions of the fluid, viz., $I$ in $2, I$ in $3, I$ in 6 and $I$ in $I 2$, and to each tube are added 3 M.H.D. of complement. The fig:ures 4.3.2.I have the same significance, as regards hæmolysis, as in the blood Wassermann results.

\section{Some Illustrative Cases.}

At the meeting lantern slides were exhibited, giving the history of certain selected cases which have a bearing on some of the points referred to in the foregoing paper. 


\section{TRANSMISSION OF SYPHILIS}

\section{CASE I}

Family : 363

Grandmother.-Had I5 pregnancies (5 miscarriages), Io children in all, two now surviving (eldest daughter, aged 66, and Mrs. S., youngest but one). Seen on 6.3.23hale and hearty: W.R. = 4.4.4.4; and again on 8.2.27 (aged 86 2/I2 yrs.) : quite well ; W.R. = 4.4.4.4.

Mother (Mrs. S.).-I.K., 8 years to I7 yearsattended Moorfields. I9II, W.R. nearly negative. I9I7, W.R. negative. Has typical Hutchinsonian teeth and corneal opacities.

Father (Mr. S.).-Said to have had syphilis and been treated.

2 I pregnancies and only 2 children surviving :-

(I) A. S.-Born May, I909. Rash at $3 \frac{1}{2}$ months; mercury by inunction and by mouth for 4 years between I909 and I9I4; W.R. fluctuated between strong positive and negative. July, I9I8, I.K. started at 9 years, given injections I2 Novarsenobillon and 6 Neo-Kharsivan (6.45 grms.), I4 Sulfarsenol (4.68 grms.). W.R. negative since I923.

(2) D. S.-Born January, I9I7. No symptoms. 23.3.I7, W.R. negative.

This case is an example of syphilis in three generations of a family, though it is impossible to say whether the mother's congenital syphilis was transmitted to her child or whether it was an instance of super-infection. The family also brings out the interesting point that an individual may have a strongly positive W.R. at the age of 86 , and yet be perfectly well and have no obvious signs or symptoms of syphilis.

\section{CASE II}

Family: 422

Grandmother (paternal).-W.R. 6.I2.2I = 4.4.4.4. Was married 8 years before first child came $=$ patient's father. He was a " healthy " baby, but had chest trouble. Fourteen years later a girl was born; she died of diphtheria at 2 7/I2 years.

Grandfather (paternal).- -Said to be healthy; was in the Mercantile Marine for a time. Died at 6o of pneumonia. 


\section{BRITISH JOURNAL OF VENEREAL DISEASES}

Father

I.I2.2I W.R. $=4.4 .4 .4$. 28.2.22 W.R. $=4 \cdot 4 \cdot 4.4$.

9.5.22 W.R. $=4 \cdot 4 \cdot 4.4$.

I7.7.22 W.R. $=4 \cdot 4 \cdot 4.4$.

Has a very big broad head.

Teeth bad, but no Hutchinsonian.

Given 20 injections S.F., July, I923, C.S. fl. = negative.

No history of syphilis or of intercourse before marriage.
Mother

I6.8.2I W.R. = Negative. 22.II.2I W.R. = Negative. 3I.I.22 W.R. = Negative. I9.2.23 Injection of 0.4 N.A.B.

2I.2.23 W.R. = Negative. 22.10.23 (3 months preg.) W.R. Negative.

Children.-(I) I920. Died in 2 months, wasting.

(2) I92I. Patient (Female) : Marasmus, rash and convulsions at 5 weeks. W.R., I6.8.2I $=4.4 .0 .0 ; 22 . \mathrm{II} .2 \mathrm{I}=$ o.o.o.o. Since then tested I922 (3 times), I923 (3 times), I924, 25, 27-always negative. Had mercury for $9 \frac{1}{2}$ months, and is now a fine, healthy girl.

(3) I924 (Male).-No symptoms. Head large and bossed, W.R. negative in 5.24 and ro.24. Died of broncho-pneumonia, January, I925. (Mother had no treatment during this pregnancy.)

(4) I925 (Male). -8 months child, died in 2 days.

This case also shows syphilis in three generations, the father in this instance suffering from congenital syphilis, and it would appear as if he had transmitted his congenital syphilis to his children in a mild form without the mother showing any signs of the disease whatever.

\section{CASE III}

\section{Family : 453}

Grandmother (maternal)._ "Paralysis" for I6 years. Had I2 pregnancies, with 4 stillborn.

Mother.-Nearly blind in right eye- " result of a fit." Has signs of congenital syphilis-rhagades about mouth and scars about joints. W.R., 5.7.2I $=4.4 . \quad$ I7.I0.22 $=$ 4.4.4.4.

Father.-W.R., I9.7.2I $=0.0 . \quad$ No history of syphilis. Married in I9I9.

(I) I920 P. B.-At $7 \frac{1}{2}$ months. 


\section{TRANSMISSION OF SYPHILIS}

(2) I92I, Patient (Female).-Peeling hands and feet at I month.

$$
\begin{aligned}
& \text { W.R., } \quad 5 \cdot 7.2 \mathrm{I}=4 \cdot 4 \cdot 4 \cdot 4 \text {. } \\
& \text {, I8.I0.2I }=4 \cdot 4 \cdot 4 \cdot 4 \text {. } \\
& \text {, } \quad \text { I3.3.22 }=0.0 .0 .0 \text {. } \\
& \text {, } \quad 6.6 .22=0.0 \text {. } \\
& \text {, } \quad \text { I7.I0.22 }=4.4 .4 .4 \text {. } \\
& \text {, } \quad \text { I9.I.23 }=4.4 .4<\mathrm{I} \text {. } \\
& \text {, } \quad 24.4 .23=0.0 .0 .0 \text {. } \\
& \text {, } \quad 26.6 .23 \text { C.S. fl. = Negative. } \\
& \text { I923, I924, I925 and I926, W.R. Negative. } \\
& \text { Is still a nervous, puny child. }
\end{aligned}
$$

(3) I923 (Male) (After mother had mercury treatment.) - No symptoms. W.R., 9.2.23 $=4.3 .2+$, o. Negative in I923 (twice, also in C.S. fl.), I924 (twice), and in I925 and I926. Had Ung. hydr. and Hyd. cum Cret. Is a strong child.

This case again shows syphilis in three generations of a family, the father showing no sign of syphilis, and giving no history. It shows further that although the congenitally syphilitic mother had a certain amount of treatment with mercury during her pregnancy, a child was born slightly syphilised. It also shows the W.R. alternating between strong positive and negative.

\section{CASE IV \\ Family: 376}

Grandmother (maternal).-Died of locomotor ataxy.

Mother.-Has typical C.S. facies. W.R., 27.9.20 = 4.2.

Father.-No history of syphilis. W.R., $27.9 .20=$ Negative.

Married, I9Io. Children :-

(I) Dec., I9II (Female).-No symptoms or signs. W.R., $28.5 .2 \mathrm{I}=4.4 .4 .4$.

(2) May, I9I8 (Male).-M.D. Unable to sit up. W.R., 7.9.20 = 4.4. Had 44 injections (I920-I92I), and W.R. negative in 1923, when his mental and physical condition had improved.

(3) February, I9I9.-Miscarriage, $\mathrm{I} \frac{1}{2}$ months.

(4) July, I920 (Female).-No symptoms. W.R. negative in September, I920, and January, I921. Mother had two injections and then developed scarlet fever. 


\section{BRITISH JOURNAL OF VENEREAL DISEASES}

(5) May, I922 (Female).-Has not been tested.

This family had already been reported by Dr. Donald Paterson in British Journal of Children's Diseases, Oct.Dec., I920.

Here again we have a family with syphilis in three generations: the mother has very typical syphilitic facies; the first child, it will be seen, has no signs or symptoms of syphilis, but has positive W.R., whereas the second child, born after a very long interval, is very severely infected, being mentally defective and having a strongly positive W.R.

\section{CASE V \\ Family: 478}

Mother.-Had I.K. at 7 or 8 years of age-in-patient at Moorfields. Now well. Teeth, incisors pegged and notched. W.R., 3.7.25 = 4.4.4.4.

Father.-Well. No history of syphilis. W.R., 3.7.25= negative. Married I92I. Children :-

(I) I922 (Male).-No symptoms or signs. W.R. and Kahn $=$ negative in 1925 .

(2) I924 (Female).-Snuffled a little and was never healthy. Hydrocephalus. C.S. fl. W.R. $=4.3$, albumen $=0.2$ per cent., sugar $=0$, cells $=200$ mononuclears per cubic millimeter, Lange 455432100o, globulin $=4$, blood W.R. = negative. Died. Marked basal meningitis. P.M.

(3) 1926 (Male).-No symptoms. W.R. and Kahn $=$ negative. June, I926.

This case again shows a congenitally syphilitic mother with a congenitally syphilitic child, and the father giving no signs or symptoms of syphilis. It is interesting to note that the first child born to the parents had no signs of the disease and that the Wassermann and Kahn reactions were negative at three years of age. It is of course possible that this child might have given W.R. for a short time shortly after it was born, as did the child in Case 2, Family: 422. It is interesting to note further that the child which drew our attention to the family had a very severe infection of its central nervous system, from which it died, and also that it had positive W.R. in the cerebrospinal fluid but negative in the blood. 


\section{TRANSMISSION OF SYPHILIS}

\section{CASE VI}

Family: Io9

Grandmother (maternal).-W.R., 5.I.26 = 4.4.4.4.

Father.-Admits no possibility of infection. W.R. and Kahn $=$ negative in 1925 .

Mother.-History of slight snuffles only. No symptoms. W.R., I925 (4 times), I926 (5 times), I927 (once.) = 4.4.4.4, in spite of much treatment.

Mother's younger brother and sister W.R. = negative.

- Married in I920. Children :-

(I) I922, S.B., at full time.

(2) Male.-Rash, desquamation and epiphysitis at I month. W.R., I4.4.25 = 4.4.4.4. C.S. fl., $5.25=$ negative. Twice later in I925 W.R. = negative, and three times in I926 W.R. = negative, but Kahn became positive.

Again a family with syphilis in three generations, the father admitting no possibility of infection and with negative W.R. and Kahn. In spite of a considerable amount of treatment, the mother's blood gave a positive W.R. persistently, and it was this fact which led me to inquire into the possibility of congenital syphilis.

\section{CASE VII \\ Family: 430}

Grandmother (maternal)._I8.I.24, W.R. = negative.

Mother.-(Probably) congenital syphilitic. No symptoms or stigmata, but W.R. very persistent. Examined I924 (5 times), I925 and I926 (each 3 times) $=4.4 .4 .4$.

Father.-Has psoriasis s.nce birth. Infection possible, but no history. W.R., 7.7.24 = negative.

Mother's Brother.-27.II.24, W.R. = 2.0.0.0. Kahn $=$ positive.

Children :-

(I) 1922 (Male).-No symptoms. W.R. negative, I924, I925 and 1926.

(2) I923 (Male).-Epiphysitis at 2 months. W.R. persistently positive I924-I927. C.S. fl. = negative.

This case is interesting for several reasons :-

In the first place the grandmother, who probably gave the disease to the two children here recorded, gave a negative W.R. when tested in I924. The mother is 


\section{BRITISH JOURNAL OF. VENEREAL DISEASES}

almost certainly a congenital syphilitic, but has no symptoms or stigmata of the disease. Her W.R., however, was very persistently positive, in spite of treatment. Her brother has been treated for an eye affection, and still has a weakly positive W.R. with a positive Kahn. Of the children, the first gives no symptoms whatever and has a negative W.R.; the second one has typical congenital syphilis, and has persistently positive W.R.

\section{CASE VIII}

Family: 433

Mother.-An illegitimate child. W.R., 3.5.26 = 4.4.4.4. $\mathrm{Had}$ an ulcerated mouth I920. Teeth very suspicious of congenital syphilis.

Father-Aged 58. Married r922. Children :-

(I) 1926 (Male). - Rash on buttocks at 8 weeks. Discharge from nose since birth. W.R., 3.5.26=4.4.4.4; I7.5.26, C.S. fl. = negative. $8.8 .26,3.1 .27,9.5 .27$, all negative.

In this case the mother appears almost certainly to be a congenital syphilitic, judging from her teeth, and the disease was present in her child, its W.R. being strongly positive for a few months shortly after birth, since when it has been negative.

\section{CASE IX \\ Family: 230}

Grandmother (maternal).-Said to be positive.

Mother.-Had treatment for I.K. before marriage, but no treatment while carrying first child. Two courses of injections and pills while carrying second child. W.R., 22.2.2I $=4 .<4.3 . \mathrm{I}, 3 \mathrm{I} .7 .23=4 \cdot 3 \cdot 3.0$.

Mother's Sister.-No signs or symptoms of congenital syphilis. W.R., I923 = negative.

Father.-Not seen.

Children :-

(I) Nov., I920 (Female).-Patient. Marasmus at II weeks. W.R., 22.2.2I and 3I.7.23= negative.

(2) Dec., I922 (Female).-No symptoms. W.R., 31.7.23 $=0.0$.

In this case the mother has congenital syphilis, but her children, judging from the W.R., have escaped it. 


\title{
TRANSMISSION OF SYPHILIS
}

\author{
CASE X \\ Family: $\mathrm{I}_{42}$
}

(Grandmother had several premature children, but no miscarriages.)

Mother.-W.R., 27.2.23 = 4.4.4.4. Has lupus erythematosus (diagnosed as Raynaud's disease) since fifteen years of age. Had I.K. in I899.

Married in I905.

(I) 1907 (Female).-Died at Io weeks.

(2) I9II (Male).-Died at 4 weeks.

(3) I9I3.-M.C. at 4 months.

(4) I9I5 (Patient).-Attended Hospital for Sick Children at six weeks for constipation (I9I5). Attended again in I920-pale and heavy-eyed. Mitral systolic murmur present. Attended r922-child pale and languid. Some ulceration of septum nasi. Mitral systolic murmur-no history of rheumatism. Six injections of N.A.B. ( $1 \cdot 05$ grm.) given in I923. W.R. negative on 27.2.23 before the injections, and on four subsequent occasions in 1923, and again in I924 and I925. Child then doing very well.

Here again the mother has undoubted congenital syphilis, but her surviving child had a negative W.R. when tested at the age of 8 years. It is of course possible that had she been tested earlier, the W.R. might have been found positive. This child could not be called a healthy child, and it is possible that she may have suffered from the effects of the congenital syphilis in her mother.

\section{CASE XI \\ Family: 4I6}

Grandmother (maternal).-Married three times. Infected by first husband. W.R., I6.6.27 $=0.0$, Kahn $=$ N.N.N. Children (by first husband) :-

(I) and (2).-P.B. at $6 \frac{1}{2}$ and 7 months.

(3) I902 (Male).-Married.

*(4) I904 (Female).-Mother of patient. (See below.)

(5) 1906 (Male).

(6) I908 (Female).-Said to be tuberculous. W.R., I927 $=0.0$.

(7)-(I0).-Said to be well.

Child by Second Husband (II) (Female).-Born I9I9. r927, no symptoms. W.R. $=0.0, \mathrm{Kahn}=\mathrm{N} . \mathrm{N} . \mathrm{N}$. 


\section{BRITISH JOURNAL OF VENEREAL DISEASES}

* Mother of Patient.-Has congenital syphilis. Said to have been born with meningitis. Eyes bad at I2 years, now blind in right eye. Ulceration of palate at I4. W.R. has been positive. She has had treatment. W.R., 22.3.27 $=$ o.o., Kahn = P.P.P.

Father of Patient.-No history of syphilis or of infection. W.R., i6.6.27 = o.o., Kahn = N.N.N.

Patient.-Born June, I926. No snuffles, rash or bullæ. Discharge from eyes-one week in March, I927. W.R., $2 \mathrm{I} .3 .27=0.0 .0 .0$. Kahn $=$ N.N.N.

Here again we have a mother with congenital syphilis and a child apparently healthy.

\section{CASE XII \\ Family: I8}

Father.-A widower with healthy children before present marriage. Had a chancre in I9I3: was treated with medicines for three years. W.R., $2.2 \mathrm{I}=4.4$.

Mother.-A widow with three children before this marriage. W.R., 2.2I $=4.4$.

Child.-(I) Aged I 7/12 years, February, I92I. No infantile history of syphilis. Brought to hospital on account of mental backwardness and inability to sit up. W.R., I5.2.2I $=0.0 ., \quad 28.2 .2 \mathrm{I}=0.0$. (after one intravenous injection of N.K.), 7.3.2I = 0.0. (after two intravenous injections of N.K.), 22.3.2I = o.o. (after three intravenous injections of N.K.). C.S. fl., albumen $=0 \cdot \mathrm{I}$ per cent., sugar $=$ slight immediate reduction of Fehling, cells $=$ Io mononuclears per cubic millimetre. Cultures: sterile, globulin $=0, W . R .=$ o.o.

Child developed whooping cough and died at home of meningitis (it is said) on I.4.2I.

In this case, although the parents both had very strongly positive W.R., the child's blood and spinal fluid on examination at $\mathrm{I} \frac{1}{2}$ years of age were both negative, although the child had an affection of the central nervous system, which was doubtless syphilitic in origin.

\section{CASE XIII}

\section{Family: 244}

L. $K-n$.-Born in I9I 5 , seen 5.2I, aged $5 \frac{1}{2}$. Discovered accidentally when doing W.R. on normal children and cases of nephritis. Admitted to hospital on account of 238 


\section{TRANSMISSION OF SYPHILIS}

nephritis. No history of syphilitic symptoms in infancy. Teeth: suggestive incisors.

$$
\begin{aligned}
& \text { W.R., 25.5.2I }=\odot .0 \\
& \text { 9.6.2I }=\odot .0 \\
& \text { I.II. } 2 \mathrm{I}=2.0 \\
& 4.4 .22=4.4 \\
& 4.7 .22=4.1 .4 . \odot \\
& \text { I9.9.22 }=3.2 .1 .0 \\
& \text { I0.6.24 }=\odot .0 .0 .0 \text { (C.S. fl. }=0.0 \text { ) } \\
& \mathrm{I} 5.7 .26=<2.0 \longrightarrow(\mathrm{Kahn}=\mathrm{N} . \mathrm{N} . \mathrm{N} \text {. }) \\
& \text { 22.7.26 (W.R. }=4.0 \\
& \text { Control done at St. } \quad\{(\text { Kahn }=\text { Doubtful }) \\
& \text { Thomas's Hospital. ( (Sigma }=0.75 \text { ) }
\end{aligned}
$$

Many other tests have been carried out, generally not absolutely negative. Kahn has never given a positive, but has been doubtful on one or two occasions.

Mother.-Married in I9II, aged 29, husband 5I.

Children :-

(I) I9I2.- Stillborn at full term.

(2) I9I4. - 8 months' baby-lived two hours.

(3) I9I5.-Patient.

(4) I9I9. - 8 months' baby, stillborn.

(5) I922. - 7 months' baby, died at I4 weeks, of pneumonia.

Mother.-W.R., I4.6.2I $=4.4 ; 4.4 .22=4.4$. Had one course of injections during pregnancy (5) in I922.

This case shows the importance of following up and inquiring into the history of a patient whose Wassermann is only very slightly positive, and it shows also how such a patient may subsequently have a strongly positive Wassermann.

\section{CASE XIV \\ Family: 25I}

E. $K-r$.-Born July, I9I9. G.P.I. No infantile history. Father.-No history of syphilis. W.R., I4.8.25= negative.

Mother.-Married in I9I7. No history of syphilis.

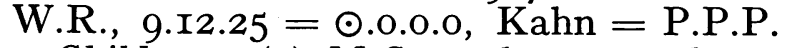

Children.-(I) M.C. at three months.

(2) Patient.-Born July, I9I9. No infantile symptoms. Mental aberrations came on insidiously in I925, and patient was admitted to hospital in July, I925. Serum W.R., 3I.7.25 $=4.4$, C.S. fl., Io.8.25 $=4.4 .4 .4$, Lange $=5555432$ II I. 


\section{BRITISH JOURNAL OF VENEREAL DISEASES}

This case is of considerable interest, inasmuch as it shows a child whose central nervous system is very severely affected by syphilis, but whose father gave a negative Wassermann and the mother practically a negative Wassermann, but positive Kahn. The child herself was very strongly positive both in the blood and the cerebro-spinal fluid. A further interesting point about this case is that the child was treated with malaria and on ordinary anti-specific lines, and in addition with salvarsanised serum intra-cisternally, after which she showed very marked improvement and the cerebro-spinal fluid became practically normal.

\section{CASE XV \\ Family: 232}

George J-s.-Born, June, I92I. Attended hospital I month for wasting, snuffles and desquamation.

Father.-Has been a soldier. No history of syphilis. W.R., 7.II.24 = I.๑.0.o., Kahn = D.D.P.

Mother.-No symptoms. W.R., I92I $=4.4 . \quad$ I923 and I924 $^{=}$negative. Married I908.

(I) I9I0.-Stillborn.

(2) I9II (Male).-No symptoms or signs of syphilis. W.R., I923 $=4 . \odot .2 .0$. Fluctuated between positive and negative from I923 to I927.

(3) I92I (Patient).--Treated with mercury during I92I.

S.W.R., I2.7.2I $=4.4 .4 .4$

, $\quad \mathrm{I} 4.3 .22=0.0 .0 .0$

," $\quad 22.1 .23=4.4$

" $\quad 28.5 .23=4.4 \cdot 3.0$

" $\quad$ I6.II.23 $=0-0$

, $\quad 4.4 .24=0-0$

,

,

",

$$
\begin{array}{r}
\text { I.8.24 }=4.4 .4 .4 \\
\left(\mathrm{Kahn}=\mathrm{P}_{\mathrm{s}} \mathrm{P}_{\mathrm{s}} \mathrm{P}_{\mathrm{s}}\right) \\
\text { I4.I0.24 }=4.4 .4 .4 \\
\text { I7.8.25 }=0.0 .0 .0
\end{array}
$$

C.S.F., II.8.24 (during fits)

(Gold $=4555432$ IOO)

$6.10 .24=4.4$

9.I2.24 $=0.0 .0 .0$

(cisternal)

23.4.25 $=0.0 .0 .0$

I7.8.25 $=0.0 .0 .0$

$\mathrm{I} 3.7 .26=0.0 .0 .0$

(Gradually improved to I7.8.25, and has been negative since to I927.)

The patient had many injections of N.A.B. and S.F. and Bismuthyl, but although at first he showed marked signs of improvement, he became gradually more and more mental and is now in an institution. 


\section{TRANSMISSION OF SYPHILIS}

(4) I922 (Female).-Born after mother had treatment. W.R. = negative from I923 to I927, no symptoms.

(5) I923 (Female).-Born after mother had treatment. $\mathrm{W} . \mathrm{R}$. = negative from $\mathrm{I} 923$ to $\mathrm{I} 926$, no symptoms.

This case brings out two important points. The first is the repeated fluctuations between strongly positive and negative exhibited by the W.R. in the blood. It also shows that treatment, although it may produce a negative W.R. in the blood and cerebrospinal fluid, need not of necessity benefit the clinical condition of the patient.

\section{CASE XVI}

Family: 252

Mary $L-s$. and family.-Seen first, November, I9I9.

Maternal Grandmother.-No history or symptoms of syphilis. W.R. = negative (9.I.20).

Father.-No history. W.R., II.II.I9 = negativealso after provocative injection.

Mother.-No history. W.R., II.II.I9 $=4.4$. Treated vigorously and became negative on 20.7.20. W.R. positive again in I92I, but negative in I922 and I923.

Children.-(I) Mary.-Born March, I9I4. No symptoms at any time. Typical Moon's molars in I922. W.R., November, I9I9 $=4 \cdot 4 \cdot 4.4$. Treated from I9I9 to I92I with injections of N.A.B. and S.F. W.R. = negative in November, I92I, and to July, I923.

(2) J. (Female).-Born July, I9I9. Rash : nephritis. W.R. = 4.4. Died.

(3) P. (Female).-Born February, I92I, after mother's treatment by injections. Quite well. W.R. = negative from I92I to I923.

This case shows how congenital syphilis may be latent in a first child, and so severe in the next child, born five years later, that the child dies very rapidly. It is altogether a difficult case to interpret, as there is no history of infection in either father or mother, and nothing to suggest the presence of congenital syphilis in the parents.

\section{CASE XVII \\ Family: 25}

$R$. $B-n$.-Born July, I9I4. Seen February, I9I8.

Father.-History of infection in IgI2. Treated for $2 \frac{1}{2}$ years. W.R., 2.6.24 = negative. $\mathrm{Kahn}=\mathrm{N}_{\mathrm{w}} \mathrm{P}_{\mathrm{w}} \mathrm{P}_{\mathrm{w}}$. 


\section{BRITISH JOURNAL OF VENEREAL DISEASES}

Mother.-Said to suffer from " kidneys and bladder." W.R., 5.7.2I = negative. Married I908.

Children.-(I) I9I0.-Died at 6 months. "Gastric." tive.

(2) I9II (Female).-Healthy. W.R., I3.Io.2I = nega-

(3) Miscarriage at 3 months.

(4) I9I4 (Patient).

(5) I9I6 (Female).-Healthy. W.R., I3.Io.2I = negative.

(6) I926 (Female).-Healthy.

Patient started snuffling at eight days old, and the nose started to flatten at three months. The bridge of the nose has been absolutely flattened since I92I. To my knowledge W.R. has never been positive, even after a provocative injection, and the Kahn reaction has been negative twice. Last test, II.7.27, W.R. $=0.0, \mathrm{Kahn}=$ N.N.N.

This has been rather a puzzling case, and it is only after repeated changes of opinion that I have come to the conclusion that it must be a specific case. The points in favour of it being syphilis are the history of infection in the father in I9I2, and the fact that the child snuffled at 8 days old. Apart from the fact, however, that the nose is absolutely flattened, there is no other evidence of congenital syphilis in the patient. I have never found his W.R. or Kahn positive. The subsequent two children are healthy.

\section{CASE XVIII \\ Family: I45}

E. F-k.-Aged II years. Seen 29.8.23. Periostitis and I.K. Maternal grandfather was in the army. Maternal grandmother had three stillbirths at full term.

Patient's Father.-Said to be healthy.

Mother.-Eldest child. Is healthy. W.R., I7.II.23= negative. (Is she a congenital syphilitic? But there is no evidence of this.)

Children. - (I) I909 (Female). - Healthy. W.R., I7.II.23 = negative.

(2) I9I2 (Female).-Patient. Early history : ? slight snuffles, did not walk till two years old. Periostitis tibiæ at nine years. I.K. shortly after. W.R., 29.8.23 = 4.4.4.4 tive.

(3) I9I4 (Female).-Healthy. W.R., 22.9.23 = nega- 


\section{TRANSMISSION OF SYPHILIS}

(4) I9I5 (Male).-Healthy. W.R., 20.Io.23 = negative.

(5) I9I7 (Female).-Healthy. W.R., I3.I0.23 = negative.

(6) and (7).-Miscarriages at three months.

This family shows a positive child sandwiched in between four negative children, none of whom shows any signs of congenital syphilis. It is true that there are two miscarriages at the end of the series, but these may or may not have been due to syphilis. 